\title{
Daniela Racheva
}

ORCID: 0000-0003-1344-7111

Sofia University „St. Kliment Ohridski”

Republic of Bulgaria

\section{СОЦИАЛЬНО-ПЕДАГОГИЧЕСКИЕ ЭФФЕКТЫ ДИСТАНЦИОННОЙ ФОРМЫ ОБУЧЕНИЯ НА ПРОЦЕСС ПРИОБЩАЮЩЕГО ОБРАЗОВАНИЯ ДЕТЕЙ В НЕРАВНОЦЕННОМ ПОЛОЖЕНИИ}

Socio-pedagogical effects of the distance form of education on the process of inclusive education of disadvantaged children

https://doi.org/10.34739/sn.2021.21.06

Аннотация: В статье рассматриваются некоторые из основных эффектов дистанционной формы обучения во время пандемии Covid-19 на процесс приобщения детей в неравноценном положении.

Ключевые слова: бедность, неравноценное положение, приобщающее образование

Abstract: The article discusses some of the main effects of distance learning during the Covid-19 pandemic on the inclusion of disadvantaged children.

Key words: poverty, disadvantage, inequalities, inclusive education

Глобальная пандемия, с которой наше общество пытается справиться уже целый год, вызвало необходимость переосмысления как места, роли и значения школьного образования, так и способа самой его реализации.

В исключительно напряжённой обстановке болгарская образовательная система была поставлена перед нелегкой задачей в сжатые сроки превратить традиционный (присутственный) школьный образовательный процесс в дистанционный. Более того - 
превратить его в эффективный, наличными к данному моменту средствами и ресурсами, способ, в максимальной степени сообразный с целями образования и воспитания, с индивидуальными нуждами каждого ребёнка и школьника и с возможно наименьшими негативными последствиями для успеваемости и развития учеников в целом. Бесспорно - это не лёгкая задача как для учителей, так и для всех участников образовательного процесса по принципу - политики, школьные руководства, педагогические специалисты, медиаторы, родители и, разумеется, сами дети.

В начальный период реализации дистанционного обучения стало ясно, что, вопреки долголетним усилиям по модернизации образовательной системы, всё ещё не до конца решены существенные вопросы, которые препятствуют восстановлению и осуществлению образовательного процесса в чрезвычайных ситуациях. В начальных этапах перехода к дистанционному обучению были констатированы существенные слабости в направлении:

$\checkmark$ информационной и коммуникационной подготовленности школьных систем к действиям в чрезвычайных ситуациях;

$\checkmark$ дигитальной подготовки части учителей и учеников;

$\checkmark$ материальной $и$ технической обеспеченности школ, учителей и учеников для осуществления дистанционного обучения;

$\checkmark$ готовности родителей исполнять образовательные функции и т.д.

Ещё в этот период среди основных проблем при реализации обучения в среде, различной от школьной, оказались и такие, которые проистекают от многоаспектных проявлений социальных неравенств - бедность, территориальная недоступность, информационная необеспеченность, сегрегация, педагогическая запущенность и т.п. Они традиционно ставят детей из различных групп и сообществ в условия уязвимости, неравнопоставленности и, соответственно, неравноценности, но редко становятся настолько осязаемыми и видимыми в ситуации, требующей срочности, а доступность имеет особое значение для обеспечения непрерывности и всеохватности предпринятых действий. 
Первоначально, индикации о наличие подобных условий были констатированы у детей из этнических меньшинств, которые традиционно причисляются к группам с высокой степенью уязвимости. Как в сми, так и в ряде исследований, реализованных в различные периоды прошлого и текущего учебного года показали, что в этих сообществах основными проблемами определяются:

- Отсутствие возможностей для технического обеспечения реализации учебного процесса в электронной среде. У большинства детей и учеников не было необходимых устройств (компьютеров, планшетов, ноутбуков) для обучения В электронной среде. Согласно результатам «онлайн исследования, в которое включились около 200 школ» одного из самых больших центров, который «работает в целях равноправной интеграции рома в болгарское общество», «в 11.68\% школ свыше 75\% учеников не имеют устройств, через которые могут участвовать в онлайн обучении» [http://www.amalipe.com/]. Поэтому во многих населённых местах осуществлялись доставки учебных ресурсов в дома учеников социальными медиаторами или самими учителями, вопреки санитарным мерам безопасности.

- Отсутствие Интернета - как в небольших и/или удалённых населённых пунктах, так и в городских кварталах, в которых проживают большие группы меньшинственных сообществ. Эти ученики оказались «на дне т.наз. „дигитальной пропасти“ (digital divide)», и вопреки быстрым действиям по подключению к Интернету в этих районах, риск «стать жертвойо дного из самых безмилостных её проявлений - „про́пасть/пробел в домашнем задании“ (the homework gap)» превратилась в реальность [Образование 2030]. Многие ученики и их семьи в этой группе не располагали достаточными знаниями для использования предоставлеными им оборудованием и Интернетом, а тем более - для выполнения учебных задач по подготовке и самоподготовке, возложенных учителем.

- Низкий образовательный уровень большинства родителей кроме того, что определяется как одна из основных причин 
материальной неудовлетворённости самой семьи, низкий образовательный уровень родителей серьёзно препятствуют реализации полноценного дистанционного обучения детей из-за необходимости родительской поддержки при усвоении и осмыслении учебного содержания.

- Не (хорошее) владение официальным языком не только детьми, но и взрослымии на данный момент является существенной проблемой, препятствующей процессу образования не только в дистанционной, но и в присутственной форме обучения.

- Прерывание процесса социального включения, который реализуется и посредством политики и практики, нацеленных на обеспечение приобщающего образования и общего развития детей. Требования социальной дистанции вызвали необходимость приостановления посещений детских садов, школ и внешкольных центров для детей, на которые возлагаются основные ожидания, направленные на предоставление общей и дополнительной поддержки личностному развитию детей и учащихся.

Впоследствии аналогичные проблемы были констатированы как в других уязвимых группах (какими являются беженцы, мигранты из третьих стран, дети в социальных учреждениях и т.д.), так и у детей из множественного сообщества, чьи семьи были затронуты экономическим кризисом в ряде секторов вследствие пандемии. Так, например, среди основных факторов, затруднивших образовательный процесс детей беженцев, - «отсутствие технических устройств, связи с Интернетом, плохие условия жизни в центрах Государственного агентства по делам беженцев, отсутствие личного пространства, неумение детей и родителей общаться на болгарском языке, отсутствие технических умений для использования платформ, отсутствие информации о проводимых новых формах обучения, ухудшенное состояние родителей (из-за потери работы и финансовых или психологических трудностей)». По мнению «большинства учителей», работающих с детьми беженцев и мигрантов, «дистанционная форма препятствует успешному изучению болгарского языка и социализации детей», что имеет 
исключительную важность для их полноценной интеграции в болгарское общество [Славкова, 2020, с. 10].

В Писме коалиции «ДЕТСТВО 2025» https://www.wearelumos.org/ о ситуации с короновирусом, адресованном Совету Министров Республики Болгарии, указывается, что констатирована «перегрузка (...) в функционировании социальных служб для детей в системе альтернативного ухода (в том числе детей, находящихся в учреждениях) и лиц, осуществляющих такой уход за ними». Эта «сверхнагруженность команд в резидентских службах» объясняется возложением «новых ответственностей» на членов команд, таких как планирование и проведение новых мероприятий, решение проблем, связанных с вызывающим поведением, порождённым изоляцией, соблюдение требований постоянной дезинфекции», дополнительная помощь детям в обучении и т.д. Среди основных проблем перед командами оказалось и предоставление дополнительных средств на питание и санитарное обеспечение детей, пользующихся социальными услугами. Это связано с тем, что «при нормальных обстоятельствах дети обедают в школе или дневном центре», в то время как в условиях социальной дистанции и дистанционного обучения «дети и юноши весь день находятся в Центрах размещения семейного типа», а средства для содержания в подобных ситуациях не предусмотрены [Детство 2025]. Проблема другого естества, касающаяся социальных услуг для детей, констатирована исследованием Eurochild. В докладе организации Growing up in lockdown: Europe's children in the age of COVID-19 указывается, что «в 2020 г. дети в Европе подвергались повышенному риску бедности», так как увеличилось число родителей, которые не могут заботитьсяо своей семье из-за снижения зарплаты или безработицы. В результате этих обстоятельств, «число детей, получающих альтернативный уход, увеличилось», как в Болгарии, так и во многихдругих странах Европы [Eurochild 2020].

Проблемы с питанием детей были констатированы не только в социальных учреждениях. В исследовании ассоциации «Образование Болгария 2030» указывается, что «для многих семей бесплатное питание в школе - единственный способ обеспечить еду 
для своих детей. До сих пор всем учащимся с 1-го по 4-й класс обеспечивается завтрак засчёт средств государственного бюджета. В соответствии со своей школьной политикой ряд школ, работающих в основном с детьми из уязвимых групп, обеспечивали так же горячий обед в школе. Оставаясь дома, большинство детей, живущих в бедности, не питаются регулярно» [Образование 2030]. По мнению Г. Митевой из объединения Национальная сеть для детей «Это ясно показывает, что кризис с коронавирусом имеет и другой, скрытый аспект. Дети не ходят в школу, но, кроме учебных занятий, часть из них лишены и пищи, которую получают, пожалуй, только там (в школе - б.а.)» [https://nmd.bg/].

Стрессовые факторы, такие как недостаток питания, экономическая нестабильность, необходимость поддержки детей в учебных занятиях со стороны родителей (особенно родителей с недостаточной или слабой педагогической компетентностью и/или низким уровнем образованности), целодневное пребывание семьи на одном месте и невозможность уединения из-за отсутствия личного пространства - всё это создало условия для возникновения высокострессовой семейной среды, в которой была сильно повышена вероятность того, что дети станут жертвами или свидетелями домашнего насилия [https://resourcecentre. Savethechildren.net, c. 3]. Тем не менее, в Болгарии и до сих пор не ведётся статистика для констатации уровня домашнего насилия и, в частности, домашнего насилия над детьми.

Вопреки действующему в стране механизму совместной работы учреждений по привлечению и удержанию в системе образования детей и учеников, всё ещё нет данных за 2020 г., сколько детей, для которых предприняты или всё ещё предпринимаются усилия по включению и удержанию в школе, остаются в системе и сколько отпали. Механизм направлен преимущественно на детей из уязвимых групп, в которых среди наиболее часто встречающихся проблем - низкая ценность образования, детская трудовая эксплуатация, ранние браки и родительство. А социальное приобщение через образование детей нацелено, не только на преодоление тенденции передачи бедности 
от поколения к поколению, а и изменение установок и стереотипного мышления в этих сообществах. В интервью автора с г-жой Л. Стояновой многолетний учитель в школе для детей в неравноценном положении в с. Рыждавица, обл. Кюстендил, рассказывает, «что пребывание в школе - условия, порядки, обучение и воспитание, которое предлагается в ней, значительно меняют навыки и взгляды детей. В школе они чувствуют себя замеченными, оценёнными, осуществлёнными и спокойными нечто, что в сообществах, в которых они рождены и в которых живут их родители, случается слишком редко. Вопреки тому, возвращаясь в семейную среду, они быстро восстанавливают свои прежние навыки и поведение, что особенно заметно по их возвращении после праздничных дней и каникул».

На следующих этапах пандемии была решена немалая часть проблем, связанных так или иначе с обучением детей на расстоянии. Так, например, для немалой части детей из этнических меньшинств, которые не располагали техническими средствами и Интернетом, было предоставлено необходимое оборудование и через дарительские кампании, и через усилия государства в этом направлении. Для детей из беженских центров также были обеспечены устройства, способствующие электронному обучению благодаря программам, реализованным Болгарским Красным Крестом. Немало школ помогли с наличной техникой детям из семей в неблагоприятном положении, чьи родители безработные, одинокие или в плохом состоянии здоровья. Болгарская образовательная система отметила значительный прогресс в дигитализации учебного процесса как в школе, так и в высших учебных заведениях. Дигитальная компетентность как преподавательского состава, так и всех участников дистанционного обучения - детей, родителей, медиаторов - заметно повысилась.

Вопреки тому, нельзя сказать, что проблемы детей, и не только находящихся в неравноценном положении, решены. Особенно в воспитательном отношении. Потому что посещение школы нацелено не только на обучение, но и на социализацию детей. В ещёболее высокой степени эти цели действительны для детей в неравноценном 
положении. Для них сама школа явлется местом, где ребёнку предоставляется возможность получить ощущение нормальности, спокойствия, понимания и развития. Местом, где ему предоставляются возможности отделиться от неблагоприятной среды, в которой он живёт, и познакомиться с многообразием мира, с возможностями для развития и личностного роста.

Именно это даёт основания сделать вывод, что дистанционная форма обучения имеет свои позитивы для обучения детей в чрезвычайных ситуациях. Но этого нельзя сказать о влиянии дистанционной формы обученияна возможности социализации, адекватные ожиданиям современного общества. Вопреки быстрым темпам развития возможностей для осуществления обучения на расстоянии, этот тип коммуникации между учителями и учениками не может заменить прямого взаимодействия в реальной школьной среде, где все участники школьной жизни взаимно обогащаются и приобретают так необходимые современному глобальному миру умения мирного совместного существования.

\section{Literature [Литература]}

Child Rights Resource Centre, The Alliance for Child Protection in Humanitarian Action and UNICEF, https://resourcecentre.savethechildren.net/.

Eurochild - Growing up in lockdown: Europe's children in the age of COVID-19, 2020 Eurochild Report, https://eurochild.org/.

Institut za izsledvane na obrazovanieto, maj 2020, http://ire-bg.org/.

Koaliciâ „Detstvo 2025” - „struktura iz 16 graždanskih organizacij i setej, rabotaûŝih s det'mi i sem'âmi vo vsej strane, https://www.wearelumos.org/.

Nacionalna mreža za decata, mart 2020, https://nmd.bg/.

Slavkova M. (2020), Gramotni i običani: decata bežanci v b"Igarskata klasna stâ̂, „Bežancite: dnes i utre - akademičen bûletin“ 2020, br. 3.

Vsički na liniâ? - Ravendost"p do distancionno obučenie, Obrazovanie 2030, 2020, http://edu2030.bg/2020/03/30/equal_access_to_online_education. 